\title{
Does Consumer Buying Behavior Change During Economic Crisis?
}

\author{
Vinod Sharma ${ }^{1}$, Jayant Sonwalkar ${ }^{2}$
}

\begin{abstract}
:
Understanding of consumer buying pattern plays the most important role in the success of any business organization. Hence, the core behaviour of consumer is also of great importance and significance for a successful marketing experience and financial affluence. However, consumer purchasing behaviour can vary severely and has a very intricate trend. Consumer buying behaviour has been attracting the studies and interest of a large amount of academician for a long time. The current financial downturn had a huge influence on the economic and social aspects of consumers around the globe. Different behaviour has been shifted through different level of economies, one of which, the Indian culture purchasing pattern. For this reason, this research is aimed to focus on the changing trends in consumer buying behaviour in the present global business crisis. This paper outlines at first, a portrait of the new consumer, highlighting its main features, derived primarily from the need for authenticity, which distinguishes it from the so called traditional consumer. Global economic crisis, which turned out to be not only a financial crisis, but also one of capitalism, the new consumer behaviour has encountered a series of changes. This paper also analyze the results of some research realized in different countries in the recession period in order to highlight the main changes occurred in the consumer buying behaviour and to draw a portrait after the economic crisis.
\end{abstract}

Key Words: Consumer Buying Behavior, Global Economic Crisis, Business Crisis, Financial Turndown

\section{JEL Classification:}

\footnotetext{
1. Assistant Professor, Medicaps Institute of Technology \& Management, Indore

${ }^{2}$ Professor of Marketing, Institute of Management Studies, DAVV, Indore
} 


\section{Introduction}

Consumer behaviour has changed greatly over the last 25 years, but it has been evolutionary and the seeds of change have been apparent for generations (Kar, 2010). The study has confirmed that the after global economic crisis led the consumers to look for new landmarks. They became more economical, more responsible and more demanding. Research conducted in different countries showed that the recession had a strong economic and social impact on consumers (Kar, 2010).

Consumer behaviour is the study of the processes that individuals or groups go through in making their purchasing choices in order to satisfy their needs. Usually the buying behaviour takes many forms of consumer's choices that can vary depending on a broad set of factors such as, earning, demographics, social and cultural factors ((Kar, 2010 \& Drakopoulos, 2008). The consumer behaviour is a combination of customer's buying awareness combined with external motivators to result in a change in the consumer's behaviour (Kar, 2010). This is why most of the economies around the globe shares one problem, because of the external influence on the internal community aspects (Chaudhuri, 2006).

The study Consumer behaviour has been so long attracting many researches because of its imperative importance to businesses around the world. By predicting consumers' behaviour, a business can understand consumers' needs, and can work on fulfilling the needs and meeting the expectations of their customers (Nistorescu and Puiu, 2009). This would eventually help businesses to maintain their prosperity and attain their long term goals. The context of this research can significantly help businesses and professionals to uncover the changes that would possibly occur to consumers' buying behaviour as a result of the global financial crisis (Nistorescu and Puiu, 2009).

During the 2007 financial crisis, the giant financial institutions and banks had collapsed. The shortfall in the US financial system and the crisis of the US subprime mortgage market had a ripple effect to other industrialized economies around the world. The crisis caused disturbances to powerful European and Asian economies putting them on the brick of deep recession. Other weaknesses in the global financial systems have surfaces. Some financial instruments were too complex and twisted which caused distrust in the global financial system. The crisis 
caused inflation and fluctuations in the prices of commodities, and hence, consumers started to take a shifted action towards their needs and wants (Nistorescu and Puiu, 2009).

The psychological outcomes of the crash has extended worldwide as businesses became receptive to the obstacles caused by this crisis especially regarding expansion of their current projects and securing capital market investments for future growth (Peter and Olson, 2007). The uncertainty that surrounded businesses have naturally affected job security for employees, consumers has faced uncertainty regarding their income, and the consumption level dropped. The sharp fall in the stock market has caused many distressful events such as, reduction in credit, bank failures, dismissal of workers, contraction in the money supply and closing down businesses (Nistorescu and Puiu, 2009).

The new financial circumstances increased panic and uncertainty among consumers. Many consumers around the world had fears related to their financial and material safety. Besides reduced employment earnings, many household lost their lifetime savings due to failure in the banking system or sharp decline in the values of their houses and stocks (Arnould, 2002). The social impacts of the financial crisis can be seen more obvious in the developing countries where the poor are being severely hurt during the crisis as demand for their labour falls, prices of essential commodities rise substantially and social services are cut. They find themselves forced to pull children out of schools and the food is being rationed among the family, with women the first to sacrifice their share (Amalia and Ionut, 2009 \& Arnould, 2002).

The general economic slowdown and rising unemployment forced household to increase working hours or send additional members to the labour force. As a consequence, household expenditure falls by as much as income (Amalia and Ionut, 2009). The consumers cannot prevent the fall in total expenditure and they tend to adjust the basket of goods purchased. For example the expenditure on food and necessities increases comparing to expenditure on clothes (Peter and Olson, 2007).

The crisis caused markets to contract and major changes appeared in their structure (Chaudhuri, 2006). The buyers changed their buying behaviour. They start to worry about their jobs and do not enjoy spending their money anymore. They postponed or reduced a big amount of purchases related to leisure and entertainment. People may 
start buying less quantities, or switch to larger size items to avoid repeated purchases. They also started to switch brands, and focus on price rather than quality and they also have started to intensify the search on the web looking for valuable bargains (Perner, 2008 \& Drakopoulos, 2008).

The role of the government is rather important to protect consumers against inflation by controlling and preventing prices from further increasing to ensure that the purchasing power of consumers will not deteriorate causing serious problems such as long term unemployment and poverty (Perner, 2008). This paper is realized first a literature review in order to identify the determining factors of the emergence of new consumer and to highlight the main features of this one. Further, through a research from secondary sources, it was analyzed the main changes occurred in the consumer buying behaviour during economic crisis.

\section{Literature Review}

Few decades ago, the driving force behind consumption was the desire of individuals to improve their social condition through possession of material goods, which ensured middle-class membership. But consumerism proved unable to make people happier, especially by the fact that it did not cause an increase in welfare in other ways than the psychological ones. Excessive consumption has created socalled "paradox of happiness", which is that once a basic level is provided, happiness does not increase with income above this limit (Drakopoulos, 2008).

Consumer choices are made increasingly more and more on the basis of social media information. In addition to deciphering the advertising message and reading the websites of companies, consumers use different online formats (forums, chats, blogs, etc.) to share ideas, to form communities and to contact their peers (Perner, 2008). As pointed by Kozinets (2010) social media is increasingly seen as a more objective source of information and all these communities have a real existence to their members and therefore have effect on many aspects of behaviour, including buying behaviour.

Lewis and Bridger (2000) show that mutations in the new consumer behaviour derives mainly from its desire to purchase authentic, stressing that the main difference between these two types of consumers is that, while the consumption behaviour of traditional consumer was largely motivated by a need for comfort, the 
new consumer behaviour is determined by looking for authenticity. Perner, (2008) stated that consumer behavior involves the study of the processes which individuals, groups, or organizations perform to acquire products, services, experiences, or ideas to satisfy their needs and how these processes have impacted the consumer and society. The role that consumers play in these days is very crucial to businesses' survival. It is the driving force behind the success of many businesses, because most of the contemporary consumers spend major time on buying decisions.

"The buying behaviour is considered a very complex phenomenon because it consists of a wide set of prior and after purchase activities" (Hansen, 2004, p. 9). The buying process consists of five stages. Starting from recognizing a problem or in other words, recognizing a need that must be satisfied, the consumer then begins to search for information related to that problem or need. After evaluating different alternatives, the consumer makes the decision to purchase the most suitable alternative and the final stage comes after purchasing, when the consumer evaluates the choice being made. There are four distinctive classes of consumer buying behaviour identified by the literature. What differentiate these classes can be observed thorough the frequency of occurrence, emotional involvement, decision making complexity and risk. These types are known to be: programmed behaviour; limited decision making buying behaviour; extensive decision-making buying behaviour and impulsive buying (Arnould, 2002).

Programmed behaviour (also called habitual behaviour) is distinguished by low complexity and little information search, this process is usually known as routine purchase of low cost items that consumer is used to buy out of habit: such as coffee, newspapers, bus tickets, etc. (Learn marketing, 2008). Limited decision-making buying behaviour involves reasonable level of decision making and relatively low amount of information search in order to generate a purchase. An example of this type can be the purchase of clothes when someone can easily get information on the product and its quality and spend short time selecting the desired outfit (East, 1997).

The extensive decision-making buying behaviour is identified as being the opposing type to the limit decision-making buying behavior (Foxall and Goldsmith, 1994). In this process the consumer would spend a relatively longer share of time in information search and would take longer period to make a decision regarding this purchase because this process is usually adopted when purchasing infrequent 
expensive product that takes a large share of the consumer's income and involves higher psychological risk (Peter and Olson, 2007).

The last type of buying behaviour identified by the literature is the impulsive buying. It is a decision made unconsciously and induced by an external stimulus that would make a specific product to appear attractive and irresistible to the consumer (Wells and Prensky, 1997). It can be seen in the four listed behaviours above, that the fundamental driving force behind these behaviour is the consumer's emotion. It is the primary determinant of buying behaviour that is highly influenced by some external and internal factors (Chaudhuri, 2006). Although emotion is a subjective issue that differs according to individual attributes and situational contexts, it is still regarded as the most elemental determinant of planned and unplanned buying behavior (Havlena and Holbrook, 1986). The unplanned behaviour matches greatly the impulsive buying which is driven mostly by emotional forces (Laros and Steenkamp, 2005).

On the other hand, the planned behaviour is a result of rationality rather than emotionality because planned behaviour is a complex process for the great deal of information needed and the long time spent on selection. Although the planned behaviour is primarily induced by emotions, it is still considered to be less emotional than unplanned. The theory of planned consumer behaviour deals with the consumer's perception of complexity. Simply stated, the planned consumer buying behaviour is explained as how difficult the consumer selects and secures a product. The level of complexity is driven by the opportunity cost of the alternatives as well as the transaction costs like time, money and effort (Ajzen, 1991).

This theory also presents the concept of 'perceived behaviour al control' as a vital component of the planned behaviour al intention. The theory explains the important role of consumer's perception of complexity as well as the essential function of risk associated with every purchase action (Posthuma and Dworkin, 2000). It is observed that as the consumer's expectation of a negative outcome increases this increases the level of perceived risk (Hansen, 2004, p. 6).

\section{The Consumer Behaviour in Response to the Financial Crisis}

The buying patterns of people tend to change during hard and stressful times such as economic crisis (Nistorescu and Puiu, 2009). The consumer reacts to any change in 
the economic situation around him by changing his consumption. This happens due to a change in the levels of his perception of risk. Financial crisis affects the customers not only economically but also psychologically. People become more money minded. They do not want to spend money on premium products anymore, even if they still could afford to do so. They only buy necessities, switch to cheaper brands and have a more rational view on promotion. They start to compare different products and select based on price compromising quality (Nistorescu and Puiu, 2009).

The buying process in this situation can be transformed from being a programmed behaviour or a limited decision-making buying behaviour to become the extensive decision-making buying behaviour. In other words the buying behaviour before the crisis was not based on extensive decision making and information gathering but after the crisis the process became more complicated. Growing unemployment, increasing inflation, "freezing" or even decreasing of wages, the decreasing of purchasing power, bad economic situation are facts that affect the consumers in almost all national markets. As long as people are reading more about economic crisis and as long as the press is focusing in reflecting the crisis effects, there is a psychological effect with negative impact on consumers (Amalia and Ionut, 2009).

The influence of the crisis on people can be reflected on their consumption. George Katona (1974) suggests that many people believe that in a few months when prices would be higher, they would have to spend more on necessities and therefore would have smaller resources at their disposal for the purchase of desirable but nonessential goods and services. Therefore inflation encourages the postponement of discretionary expenditures. G. Katona (1974) also believes that during recession people are motivated to save because of threats related to their jobs or income. The saving rates decline as economic conditions improve. He suggests that saving more or less is influenced by economic and psychological factors. But during hard times it is difficult for some people especially those have been harmed directly either by decreasing wages or those who were forced out of their jobs to save money because they are left with less money that they rather have to spend on necessities.

In their study, P. Amalia and P. Ionut (2009) show that people are not the same and not all the people have the same perception about a situation with negative effects like economic crisis. The most important factors which model the consumer's behaviour in such a situation are: risk attitude and risk perception. Risk attitude reflects consumer's interpretation concerning to the risk content and how much he or 
she dislikes the content of that risk. Risk perception reflects the interpretation of the consumer of the chance of being exposed to the risk content. Using the risk attitude and risk perception factors, consumers can be segmented to:

- The panicked consumers: are those who have a high risk attitude and a high risk perception. This kind of consumers is in an immediate stressful situation. They are high risk averse and will try to avoid the risk. These consumers tend to over react in crisis context. Any way it is expected that panicked consumers to drastically cut their spending, to reduce consumption and switching brands even product categories. They will eliminate major purchases and will be focused on looking for best price. Thus, they are not loyal to any brand; they are loyal only to the best price.

- The prudent consumers: are those who have high risk attitude and low risk perception. Even if these consumers: they are risk averse and consider that they are not in an immediate stressful situation because they are not high risk exposed. Thus, these consumers are very prudent and carefully plan their spending, postpone major purchases, in some cases switching brands, they are very well informed in the purchasing process.

- The concerned consumers: are those who have low risk attitude and high risk perception. Even if these consumers consider that they are high exposed to the risk content they are not risk averse and usually they assume risks. So their behaviour is determined first by the risk perception. This type of consumers will plan their spending. This could happen only in case of risk perception increasing. Also, this category will continue to do major purchases but only if they make a "good deal". If risk perception is increasing they will tend to postpone major purchases. They tend to remain loyal to the brands but in some cases they are able to switch to less priced options, in these cases companies could introduce a lower version of the premium or middle brand in their portfolio to retain them. Also it is interesting that this type of consumers is ready to try new and innovative products in spite of the hard times.

- The rational consumers: are those that have low risk attitude and low risk perception. So they are not risk adverse and consider that they are not exposed to the risk content. They avoid the information concerning to the crisis effects and generally they maintain their "usual behaviour". It is expected that these consumers will not reduce their spending, and will continue to buy their favourite brands and try the innovative products. 
According to Ang S. H. (2001), these changes in consumption behaviour arising from an economic crisis may be moderated by personality characteristics. These include the degree to which consumers are risk adverse, value conscious, and materialistic. Risk aversion pertains to the degree to which an individual feels comfortable with unfamiliar circumstances and is willing to undertake chances. Value consciousness refers to the importance an individual places on getting the best deal or quality for a fixed price. Materialism concerns the importance an individual places on physical possessions as a reflection of his station in life to others.

New trends in consumer behaviour emerged as a result of the economic recession. A study conducted by Paul Flatters and Michael Willmott (2009) identified these new trends.

- A demand for simplicity: during recession consumers are used to limited offers and they tend to simplify their demand, so after the crisis it is expected that consumers will continue to buy simpler offerings with greatest value.

- Discretionary thrift: even the rich people are economizing, although they don't have to. They revealed their dissatisfaction with excess consumption. They started to recycle, buy used goods and teach their children simple and traditional values.

- Mercurial consumption: Today's consumers are 'agile' they act fast in response to price change, and have the ability to switch brands looking for the least price sacrificing the quality and loyalty.

- Green consumerism: this trend has slowed during the recession because people are not willing to pay more for products that has close substitutes with cheaper price. The demand for green, environment friendly has declined but it is anticipated to recover after the recession.

- Ethical consumerism: people are less donating for charity, animal welfare etc, because they are focusing on their families' welfare. This trend is expected to recover slowly after the recession.

The results of an online survey, realized by Market Probe International (in 2009 and 2010), on 5700 adults in 7 markets (SUA, Brazil, UK, France, Netherlands, Japan, China) show three keys to understanding the relationship between consumers and society in the post-crisis period:

- "In USA $90 \%$ of US consumers believe that they are currently living in a recession. This is an indication of how recession caused by the financial crisis influenced consumer behaviour. $56 \%$ of US consumers feel that their 
lifestyle has been impacted by the recession. Suddenly, consumers were forced to revalue their spending and shopping choices. For $72 \%$ of US shoppers, lower prices have a high amount of influence over where people do their shopping".

- "The same survey was conducted in Spain and the results showed that $82 \%$ of Spanish consumers believe that they are currently living in a recession. $53 \%$ of Spanish consumers feel that their lifestyle has been impacted by the recession. More than one-in-three UK consumers experienced a worsening financial situation, falling job security and falling confidence in the housing market in 2008 and 2009".

- "In the South East Asia, 78\% of Chinese customers have felt some impact from the financial crisis and middle-class consumers in the 19 to 45 age group are feeling the most pressure. (82\%) of South Korean consumers believe that they are currently living in a recession. Over one-third of Japanese shoppers are giving up some of their favourite brands to save money".

- "In the Arab world about (59\%) of consumers in the United Arab Emirates (UAE) and $30 \%$ in Saudi Arabia believe that their country is in a state of recession, research shows that consumers are adjusting their consumption behaviour s. (38\%) of Saudi and (37\%) UAE consumers have changed their lifestyle as a response to the global economic downturn. Luxury brands have become an essential part of the Saudi Arabia and UAE standard of living as consumers are willing to pay higher prices for products that they believe will bring them social status".

\section{Transformation In Consumer Buying Behaviour During The Economic Crisis}

The global economic crisis has determined many changes in the consumer behaviour and has led the vast majority of consumers to look for new landmarks: they became more economical, more responsible and more demanding. Many market researches realized in the last three years showed that.

An U.S. study realized in 2009 by Booz \& Company, which involved a total of 2000 consumers, confirmed that a "new frugality" appear at the beginning of the recession and highlighted the first two years of declining consumption per capita, was so 
strongly rooted among American consumers and it changed their consumption patterns in such a manner that is expected to persist even if the economy recovers.

This new frugality, characterized by a strong awareness of the value that dictates compromises in terms of price, brand and comfort, became the dominant mentality among U.S. consumers, as shown by M. Egol, A. Andrew Clyde and K. Rangan (2010).

The study mentioned above revealed that $65 \%$ of American consumers increasingly using coupons more often, preferring to buy at low prices at the expense of comfort shopping, focusing on saving. The new frugality and value consciousness, which now directs consumer behaviour, does not apply to products such as "opening price point" (OPP) (produced with the lowest prices at branded retailers). Consumers continue to buy the products at different prices, in turn they need more reasons to justify the purchase, regardless of price segment of which the product belong. They refuse to buy at higher price unless they clearly perceive quality advantage. If they are loyal to some brands, they prefer to wait for a price drop, by promotions or discount coupons.

Inherent behavioural differences in this new frugality are reinforced by demographics, including income, gender, ethnicity and age. For example, although in general, consumers buy products in different price categories, there are certain segments of the population (such as women, people with low income, middle-aged people) seeking to make savings, buying products at reduced prices (Egol et al., 2010).

A study made in 2009 on a sample of 2400 people in France, U.S. and UK, by Euro RSCG C\&O, in partnership with Harris Interactive, was aimed at understanding the factors that influence preferences and consumer choices and sketching a portrait of him after the crisis. The study showed that most consumers surveyed changed their consumption behaviour by adopting a logical standby or a replacement, distinguishing their purchases or dropping different brands.

Thus, before being interested in the price of products, consumers are asking questions about their usefulness $(64 \%$ of respondents wonder whether they really needed, $60 \%$ if the product could not find a lower price elsewhere and $59 \%$ if they can afford to acquire). In the context of crisis, perhaps contrary to many 
expectations, quality is what comes first for the consumer before the lower price. Consumers surveyed defined quality by: looking for healthy products (42\%), looking for strong and sustainable products (47\%) and for responsible products (http://www.eurorscgco.com).

\section{Proposed Solutions \& Recommendations}

The government role is fundamental in trying to overcome some problems associated with the Global Financial crisis. Its intervention is essential to ensure that consumers are not affected adversely by this crisis by subsidizing the essential commodities like food. This would prevent increasing the prices in the future. Controlling the prices would be in favour of the consumers who have lost their jobs, wages and life time savings. There is a need for government to provide regulations to protect consumers from the effect of the global financial crisis, especially the poor.

Government must take actions to restore responsibility, accountability and transparency to the national and international markets by creating legislative and institutional structures to reduce undesirable effects of the global financial crisis especially in the financial sector due to its vital role which affects all the aspects of society.

Government should be ready to step in especially after the credit squeeze which has affected vital services and this harmed the poor especially in food and housing sectors. It should put restrictions on businesses that do not work in favour for consumers. Education is a fundamental factor that assists consumers to take more rational decisions regarding the uses of their disposable income. This is rather impossible for a population where financial studies are not part of their compulsory education. It is highly suggested that financial studies to be included as appropriate in the public schools as a core subject to be studied by all students.

Banks and Financial institutions have an incredibly important role to help avoid another financial crisis by simply explaining to their clients the nature and features of their financial products. By clarifying the consequences of acquiring this particular product consumers can avoid loans or credit that are hard to repay or a very risky investment. There is a need to spread the awareness through consumer 
protection associations, to help consumers achieve the greatest possible benefit using their disposable income. Many consumers especially the illiterate don't have knowledge of the effects of the financial crisis and find it hard to cope with the difficult circumstances that the whole world is living through. Consumers should start focusing on long term planning. They must plan for their kids' future to be able to meet financial obligations for their college tuition. Saving is an important action toward securing for retirement period. It is a way to remain financially stable and normally feel more secure. In order to be able to increase the savings plan, consumers have to follow the planned behaviour suggested by the literature earlier. By planning the purchases ahead of time consumers can avoid extra spending caused by unplanned purchases and as a result saving rate will increase. To avoid the problems associated with rising healthcare cost it is very crucial to set aside money in a dedicated healthcare savings account or keep a credit card on hand in case of emergencies.

\section{Conclusion}

The world is facing tremendous economic challenge. The US subprime crisis in 2007 negatively affected a number of well-developed economies including India. The financial crisis is known as a multi-dimensional trend, which has various impacts on economic stability and social life. In this context it is highly observed that one of the most rigorously impacted sections of the Indian economy was the consumer buying behaviour.

Consumer buying behaviour is seen as a collection of decision-making processes, which are determined by some internal and external factors. However, the most influential factor is recognized to be the external economic instability that Indian consumers experience. The depressing effects of the financial crisis have hit the overall consumers purchasing behaviour effecting both planned and unplanned buying behaviour.

Every feature of the socio-economic situation has substantially changed not only the way the consumer purchases, but especially what they are buying and why they are buying. In developed countries, consumers are more economical, more responsible and more demanding than traditional consumers. Currently, consumers are increasingly aware of all aspects involved in purchase of products, from design, safety, and origin to their social and economic impact. Thus, consumers have 
become more vigilant and more aware of their ability to influence the world with their consumer choices (Salzman and O'Reilly, 2010).

During the economic crisis a series of parallel steps have made their presence, resulted in the consumer orientation on organic products or on fair trade products. Thus, a particular point of view, the crisis served as a mini electric shock, announcing a new era, maybe the era of responsible consumption.

In Mansoor (2011) opinion, the main changes in the new consumer behaviour, which are the result of economic recession, could be summarized as follows:

- The need for simplicity: During recession consumers are accustomed to limited offers and tend to simplify their demands, so that after the crisis is expected that they will continue to accept simple offers, but with greater utility.

- Temperance: Even rich people save, although they are not required to do so. This is one way they show their dissatisfaction on excessive consumption. They began to recycle and to teach children traditional values.

- Smart consumption: Consumers today are 'agile' and act quickly to price changes, with the ability to change brands looking for the lowest price, sacrificing the quality and loyalty.

- Green consumerism: This trend slowed during the recession because people are not willing to pay more for certain products that can be substituted with others with cheaper price. The demand for environmentally friendly products has declined during the economic crisis, but anticipated a recovery after the recession.

- Ethical consumerism: People are less willing to charity actions, because they are more concerned about the welfare of their families. In this case, is expected to rebound slowly.

In author's opinion, there are many models available on consumers purchase behaviour in different situation but there is no model available on consumer purchase behaviour so the work has to be done on this area to prepare a model during economic crisis.

\section{References}


Ajzen, I. (1991), “The Theory of Planned Behaviour”, Organizational Behaviour and Human Decision Processes, 50, pp 179-21.

Amalia, P. and Ionut, P. (2009), "Consumers' reaction and organizational response in crisis context", Uni. Of Oradea. The Journal of the Faculty of Economics, 1(5), pp. 779-782.

Ang, S. (2001), "Personality influences on consumption: insight from the Asian economic crisis", Journal of International Consumer Marketing, 13 (1), pp. 5-20.

Arnould, E., Price, L. and Zinkhan, G. (2002), “Consumers", (2nd ed.). McGraw-Hill, New York.

Chaudhuri, A. (2006), "Emotion and Reason in Consumer Behaviour", ButterworthHeinemann, London.

Drakopoulos, S. (2008), "The paradox of happiness: towards an alternative explanation", Journal of Happiness Studies, Volume 9, No. 2, pp.303-315.

East, R. (1997), “Consumer behaviour: Advances and applications in marketing”, PrenticeHall, London.

Egol, M., Andrew, C.A. and Rangan, K. (2010), "The New Consumer Frugality", www.strategybusiness. com/article/00023?pg=all, Accessed on: 20/06/2012.

Euro RSCG Worldwide (2010), "The New Consumer in the Era of Mindful Spending", Prosumer Report, volume 8, 2010.

Euro RSCG Worldwide (2010), “The Emergence of the New Consumer”, Prosumer Report, volume 11, summer 2010 http://www.eurorscgco.com/Upload/Actualites/CPEtudeCri, seetConsommation.pdf

Flatters, P. and Willmott, M. (2009), "Understanding the postrecession consumer", Harvard Business Review, 7(8), pp. 106-112.

Foxall, G. and Goldsmith, R. (1994), "Consumer psychology for marketing”, Routledge, London.

Hansen, F., Percy, L. and Hansen, M. (2004), "Consumer choice behaviour - an emotional theory", research Paper, Copenhagen Business School. Denmark.

Kar, M. (2010), "Consumer behaviour over the last 25 years", Oxirm Research Themes, Oxford Institute of Retail Management, The Retail Digest, pp. 46-53.

Katona, G. (1974), "Psychology and Consumer Economics", Journal of Consumer Research, $1,1-8$.

Kozinets, R. (2010), “The Field Behind the Screen: Using Netnography For Marketing Research in Online Communities", Journal of Marketing Research, Number 39, pp. 6172.

Havlena, W. and Holbrook, M. (1986), "The varieties of consumption experience: comparing"

Laros, F. and Steenkamp, J.B. (2005), "Emotions in consumer behaviour: hierarchical approach.” Journal of Business Research, 58 (10), pp. 1437 - 1445.

Learn Marketing (2008), “Consumer buying behaviour", [Online] Available: http://learnmarketing.net/consumer.htm, (July12, 2010). 
Lewis, D. and Bridger, D. (2000), "The Soul of the New Consumer: Authenticity What We Buy and Why in the New Economy", Nicholas Brealey Publishing, London.

Mansoor, D. (2011), "The Global Business Crisis and Consumer Behavior: Kingdom of Bahrain as a Case Study", International Journal of Business and Management, Vol. 6, No. 1; January 2011, pp. 104-115.

Nistorescu, T. and Silvia, P. (2009), "Marketing strategies used in crisis - case study", MPRA Paper 17743, University Library of Munich, Germany.

Onete, B., Voinea, L. and Dina, R. (2010), "Dimensions and Evolutions of the New Consumer Concept in Romania", Current Issues in Business and Law Journal, nr. 5 (2), 2010, Vilnius, Lituania, pp. 341-355.

Perner, L. (2008) "Consumer behaviour: the psychology of marketing; Uni. of Southern California", [Online] Available: http://www.consumerpsychologist. Com, (August 7, 2010).

Peter, P. and Olson, J. (2007), “Consumer Behaviour”, McGraw-Hill, London.

Posthuma, R., and Dworkin, J. (2000), "A behavioural theory of arbitrator acceptability", International Journal of Conflict Management. 11 (3), pp. 249-266.

Salsberg, B. (2010), “Japanese New Consumer”, McKinsey Quarterly, Issue 2, p80-87.

Salzman, M. and O'Reilly, A. (2010), "Trends in Mindful Consumption", http://www.thenewconsumer.com/2010/10/29/10-trends-inmindful- consumption/, Accessed on: 24/06/2012.

Ulvoas-Moal, G. (2010), "Exploring the Influence of Spirituality: A New Perspective on Senior Consumers' Behavior”, Advances in Consumer Research (Volume 37), pp. 917 919.

http://www.researchandmarkets.com/reportinfo.asp?cat_id=0\&re port id=1057010\&q=The Global Economic Crisis: The Impact on Consumer Attitudes \& Behaviours in the United States\&p=l, Accessed on: 16/06/2012.

http://www.sequovia.com/actualites/2254-le-nouveauconsommateur-en-attentede-marquesplus-humaines-etresponsables, html, Accessed on: 20/06/2012. 